\title{
Getting Told and Being Believed
}

\section{Citation}

Moran, Richard. 2005. Getting told and being believed. Philosopher's Imprint 5(5): 1-29.

\section{Published Version}

http://hdl.handle.net/2027/spo.3521354.0005.005

\section{Permanent link}

http://nrs.harvard.edu/urn-3:HUL.InstRepos:10121963

\section{Terms of Use}

This article was downloaded from Harvard University's DASH repository, and is made available under the terms and conditions applicable to Other Posted Material, as set forth at http:// nrs.harvard.edu/urn-3:HUL.InstRepos:dash.current.terms-of-use\#LAA

\section{Share Your Story}

The Harvard community has made this article openly available.

Please share how this access benefits you. Submit a story.

\section{Accessibility}




\section{Getting Told and Being Believed}

\author{
Richard Moran
}

Philosophers' Imprint

$<w w w . p h i l o s o p h e r s i m p r i n t . o r g / 005005 />$

Volume 5, No. 5

August 2005

(C) 2005 Richard Moran
Recent interest in the epistemology of testimony has focused attention on what justification we may commonly have in the vast areas of life where we are dependent on what other people tell us. This dependence is not restricted to what we are told in face-to-face encounters, for we also take ourselves to know all sorts of things that only reached us through a long chain of utterances and documents, whose evidential status we have never investigated for ourselves and will never be in a position to investigate. And the content of such knowledge is not confined to the arcana of specialized studies but includes such mundane matters as the facts of one's own birth and parentage, the geographical and institutional facts of one's immediate environment, and the general facts that make up one's basic sense of what the world is like.

In part it is the enormity of this dependence that makes for the interest in the subject of testimony, combined with the apparent clash between the kind of epistemic relations involved here and the classic empiricist picture of genuine knowledge basing itself either on direct experience of the facts or on working out conclusions for oneself. ${ }^{1}$ It isn't just that the bulk of what we take ourselves to know is so highly mediated, as even knowledge gained through a microscope or other scientific instrument must be; rather it is that the vehicle of mediation here-what other people say-seems so flimsy, unregulated, and is known in plenty of cases to be unreliable, even deliberately so. People do lie, get things wrong, and speak carelessly. And while we may realistically

${ }^{1}$ Cf. Locke: "For, I think, we may as rationally hope to see with other Men's Eyes, as to know by other Men's Understandings. So much as we ourselves consider and comprehend of Truth and Reason, so much we possess of real and true Knowledge. The floating of other Men's Opinions in our brains makes us not a jot more knowing, though they happen to be true" (Essay Concerning Human Understanding, 1, 4, 23).

Richard Moran is Professor of Philosophy at Harvard University. 


\section{Richard Moran}

hope for continued improvement in the various technical means of epistemic mediation (advances in scientific instrumentation are part of the history of scientific progress, after all), there is little reason to expect that the fallibility and mendacity associated with human testimony will one day be overcome. So in this light, reflecting on just how much we rely on the word of others, we may conclude that either we are very careless believers indeed, with no right to claim to know more than a fraction of what we think we know, or some great reductionist program must be in the offing, tracing this chain back to something resembling the classic picture of knowledge by acquaintance. ${ }^{2}$

Hume's famous discussion of the believability of reports of miracles is the locus classicus for attempts to understand the epistemic status of testimony as ultimately the same as that of any other reliable evidence. ${ }^{3}$ And part of what is meant by this claim is that the basis we may have in any given case for believing what we hear can only be an a posteriori judgement to the effect that in this case there is a reliable evidential correlation between the statement we are being offered and the facts themselves. Several recent writers, most notably C. A. J. Coady in his book Testimony, ${ }^{4}$ have argued that the Humean picture cannot succeed in rieconstructing our actual basis for believing what people say, and that our entitlement to believe what we are told must have, in part, an a priori basis. Somewhat lost in much recent discussion, however, is attention to the basic relationship between people when one person tells a second person something and the second person believes him. This is the primary everyday occurrence, and it is the basic way knowl-

\footnotetext{
${ }^{2}$ Or back to observation sentences. Cf. Quine and Ullian (1970), pp. 33-35, which makes explicit comparison of testimony with the "extension of the senses" provided by telescopes and radar.

${ }^{3}$ On Miracles', in An Enquiry Concerning Human Understanding.

${ }^{4}$ Testimony: A Philosophical Study (Oxford, 1992).
}

\section{Getting Told and Being Believed}

edge gets around. Or at least, so we say. For normally (though not without exception) we take it to be sufficient for someone's being brought to know that $\mathrm{P}$ that they were told by someone who knew, and they believed him. And now, of course, if this person is taken to know that $\mathrm{P}$, he may tell another person, and so on. This may seem absurdly simple and unreflective, and to be at odds with an earlier picture of genuine knowledge as being more of an achievement lying at the end of an arduous path from belief or opinion. My concern in this paper, however, is not so much with the conditions for knowledge as with the nature of the two sides of the relationship described here. One person tells the other person something, and this other person believes him. I want to understand what 'telling' is, especially as this contrasts with other things done in (assertoric) speech such as persuading, arguing, or demonstrating; activities which may also lead to belief or knowledge for the interlocutor, but in importantly different ways. And primarily I want to examine the relation of believing where its direct object is not a proposition but a person. For in the basic case described above, it is the speaker who is believed, and belief in the proposition asserted follows from this. These are different epistemic phenomena. For the hearer might not believe the speaker at all, taking him for a con man, but yet believe that what he has said is in fact true. Whereas when the hearer believes the speaker, he not only believes what is said but does so on the basis of taking the speaker's word for it. I don't mean to suggest that this distinction has been wholly ignored in the literature of testimony, and I will soon come to discuss what I think is the best recent discussion of it. But both it and the distinction between the speech-act of telling and other things done with assertion have not been given a central place in the discussion of what is distinctive about the epistemic dependence on testimony. Specifically, I wish 


\section{Richard Moran}

to argue that any account of testimony that seeks to resist the (Humean) assimilation of its epistemic status to that of an evidence-like correlation between one set of phenomena and another will have to give a central place to the distinctive relation of believing another person. ${ }^{5}$ Only in this way can we account for what is distinctive about acquiring beliefs from what people say, as opposed to learning from other expressive or revealing behavior of theirs. The hope is to show that the paradigmatic situations of telling cannot be thought of as the presentation or acceptance of evidence at all, and that this is connected with the specifically linguistic nature of the transfer of knowledge through testimony (which will take us through an epistemological reading of Grice's original account of non-natural meaning).

\section{Evidential Relations and the A Priori}

It is in part due to the epistemological context of recent discussion of testimony that argument has focused on the question of the a priori or a posteriori status of our justification for beliefs acquired in this way. In recent work, both C.A.J Coady and Tyler Burge have argued against a broadly Humean picture, by attacking the idea that we could only have a posteriori justification for believing what others tell us. ${ }^{6}$ Coady presents more than one argument against the Humean idea, but several of them begin with the following strategy. If we can only have a posteriori grounds for taking what people say to be a reliable guide to the facts, then on such a view it must be conceivable for there to be a community of speakers whose assertions bore no reliable relation to the facts. If we are to be in a position to deploy an a posteriori argument for the existence of such a correlation, it must be

${ }^{5}$ I follow other recent writers in characterizing this as a Humean position, but I don't argue for the attribution. For a dissenting view, see Saul Traiger (1993).

${ }^{6}$ Coady, op. cit., and Tyler Burge (1993).

\section{Getting Told and Being Believed}

possible for us to begin confronting the linguistic evidence without begging that very question. Coady presents a powerful and connected set of arguments for the conclusion that this is not, in fact, a coherent possibility. Not only would the practice within the community of making or accepting assertions soon break down on such assumptions, but from a perspective outside the community there are deeper reasons connected with the interpretation of speech which prevent the Humean scenario from being realizable. For assigning content to the utterances of the hypothetical speakers requires, for familiar reasons, regular correlation between assertive utterances and the conditions under which they would be true. Massive disparity between the content we assign to utterances and their truth or rationality would oblige us as interpreters to revise our original assignments of content to them. So there is, in fact, no genuine possibility of a community of speakers whose assertions failed, as a general rule, to correlate with the facts. And thus, contrary to the Humean picture, our general justification for believing what people say cannot be a purely empirical, a posteriori one. ${ }^{7}$

Both arguments direct themselves against the idea that we have, at best, empirical, inductive grounds for believing what people say. I don't dispute this general point or the

7 Burge's argument is very different, and I will not be examining its details here. In particular, unlike Coady as we will see, his account does not appeal to a principle of charity in the situation of radical interpretation. What it shares with Coady's argument is the aim of providing some a priori warrant for believing what is said. Burge argues for what he calls the Acceptance Principle, which states that "A person is entitled to accept as true something that is presented as true and that is intelligible to him, unless there are stronger reasons not to do so" (467). He states that this is "not an empirical principle" (469). And the general form of justification associated with it is meant to apply equally to our epistemic dependence on other people ("rational sources") and to our dependence on certain capacities, what he calls "resources for reason", such as memory and perception (469-70). By contrast, for my purposes the difference between our dependence on memory and perception and our dependence on other people is allimportant for the understanding of testimony. 


\section{Richard Moran}

particular way it is argued for in these two instances, but I do want to point out that this general form of argument describes no particular role for the notions either of a speaker's telling someone something or of believing that speaker. What the generality of such arguments provides is a defeasible $a$ priori warrant for believing that what other people say will normally be true. But any argument pitched at that level of generality will leave untouched the question of whether believing the person (as opposed to believing the truth of what is said) is a legitimate, and perhaps basic, source of new beliefs. For we might well have an a priori defeasible warrant for accepting the beliefs we gain through observing the behavior of others (verbal and otherwise) without this warrant's involving the concepts of 'saying' or 'telling' at all. By itself, such a justification is no different from the presumptive right we may have (ceteris paribus) to rely on the deliverances of the senses or of memory. At this level of argument, the speech of other people could still be something which is treated as evidence for the truth of various claims about the world; the difference would only be that here we may have some non-empirical right to treat this phenomenon as evidence, perhaps even very good evidence. ${ }^{8}$ This general line of thought begins, then, to look more like a non-skeptical version of the basic Humean view, and less like a vindication of testimony as a distinct source of beliefs, one not reducible to a form of evidence. And yet it is the special relations of telling someone, being told, and accepting or refusing another's word that are the home of the network of beliefs we acquire through human testimony. And these relations, I hope to show, provide a kind of reason for belief that is

${ }^{8}$ Summarizing his line of criticism of one version of the reductionist thesis associated with Hume, Coady says, "The difficulty consists in the fact that the whole enterprise of $\mathrm{RT}^{\prime}$ in its present form requires that we understand what testimony is independently of knowing that it is, in any degree, a reliable form of evidence" (p. 85).

\section{Getting Told and Being Believed}

categorically different from that provided by evidence.

Another way of putting this criticism would be to say that arguments of the generality of Coady's do not address the question of what is distinctive about acquiring beliefs from what people say, as compared with other things people do. At bottom, the epistemological role of communicative speech is not seen as essentially different from that of other behavior. But the observable behavior of other people may be a source of true beliefs in all sorts of ways, which need have nothing to do with believing the other person. I may look out my window on a sunny day and see people bundled up against the cold and then reliably conclude from this that it must be colder outside than it otherwise looks. This transition in thought is not essentially different from the picture according to which I observe the verbal behavior of some exotic community and, in seeking to understand what it means, necessarily rely on various assumptions about their rationality and general awareness. And here one could point out that the same "rationalizing" or charitable constraint on understanding what these people say also provides a defeasible warrant for taking what we understand them to say to be true. This is because we take their speech normally to express their beliefs, and we take their beliefs (as interpreted by us) normally to be true. This familiar, general scheme applies in the same way to the behavior of the people I see bundled up against the cold, and to the verbal behavior observed by the Radical Interpreter. Pictured in this way, one's relation to the exotic speech community does not involve being told anything at all, or believing them, any more than it does in the case of the people observed from the window. In both cases it is just a matter of an inference from behavior which is seen as rational to some conclusion about the state of the world. So nothing along these lines, justify- 


\section{Richard Moran}

ing the beliefs we acquire from other people, can count as a vindication of our reliance on testimony, since it is not a vindication of what we learn through believing other people.

This is, of course, the familiar role of speech and its relation to belief in contemporary philosophy of mind, and it should not be surprising to see it exerting a degree of control over the recent discussion of testimony. Within this discourse, speech is seen as a kind of interpretable human behavior like any other. When we interpret such behavior, we seek to make it understandable within the rational categories of what is called "folk psychology", and ascribe beliefs and other attitudes which will be reasonable approximations to the True and the Good. And this picture of our relation to the speech of other people leads almost imperceptibly into a view about testimony. For we can argue from here: when we interpret the speech of another we do not only learn about the speaker; we also learn about the world. Most obviously, when someone makes an assertion we may not only learn about what he believes, but if the assertion is true, we may also learn the truth of what is asserted. And if our interpretation is guided by principles of charity, we will indeed take most of what people say to be true, even in cases where we have no independent reason for thinking it true. In this way, the fact of the other person's belief (as interpreted by us) may function as our reason for believing the same thing. We thus gain true beliefs about persons as well as about the world they are talking about.

\section{Perversity, Dependence, and Risk}

What this general scheme provides us with is a presumptive right to share the beliefs we take the speaker to have. But other things being equal, we would have the very same right

\section{Getting Told and Being Believed}

however we learned of that person's beliefs. ${ }^{9}$ The epistemic warrant described in this scheme need not involve a dependence on speech any more than it did when I learned about the weather by seeing how people outside were dressed. Speech, of course, can be an especially revealing and fine-grained basis for belief-ascription, but from this perspective it is but a particular instance of the more general scheme of interpreting behavior.

Since it is knowledge of the other person's beliefs that is doing all the epistemic work on this picture, we should note that while speech is in some obvious ways a privileged route to such knowledge, it is also one which subjects the interpreter to special risks which are not shared by other possible ways of coming to this same knowledge. When I learn of someone's beliefs through what they tell me, I am dependent on such things as their discretion, sincerity, good intentions - in short, on how they deliberately present themselves to me-in a way that I am not dependent when I infer their beliefs in other ways. People are known to lie, exaggerate, and otherwise speak in ways that do not express their genuine beliefs. Thus, in relying on what a person says, I am incurring an additional risk that the behavior he is manifesting may be deliberately calculated to mislead me as to what he believes. I am here dependent on him, and his intentions with respect to me, and not just on my own abilities as an interpreter of the evidence. This source of error is a much more remote possibility in the case of inferences drawn from the private observation of someone's behavior. The people bundled up against the cold could be dressed up like that just so as to fool me, but this is hardly the everyday occurrence that lying and misrepresentation are. And that

\footnotetext{
${ }^{9}$ With some obvious exceptions; for instance, if I learned of his beliefs from the bragging admission of the person who deceived him. But these sorts of cases are just what is taken to be excluded by speaking of "other things being equal".
} 


\section{Richard Moran}

risk of error is not a possibility at all for those ways, real or imaginary, of learning someone's beliefs directly and without the mediation of voluntary expression or behavior at all (i.e., whatever is imagined in imagining the effects of truthserum, hypnotism, or brain-scans). If the epistemic import of what people say is at bottom that of an indication of what they believe, it would seem perverse for us to give any privileged status to the vehicle of knowledge (speech and assertion) where we are most vulnerable because most dependent on the free disposal of the other person. And if we are considering speech as evidence, we will have eventually to face the question of how recognition of its intentional character could ever enhance rather than detract from its epistemic value for an audience. Ordinarily, if I confront something as evidence (the telltale footprint, the cigarette butt left in the ashtray) and then learn that it was left there deliberately, even with the intention of bringing me to a particular belief, this will only discredit it as evidence in my eyes. It won't seem better evidence, or even just as good, but instead like something fraudulent, or tainted evidence.

Insofar as speech does occupy a privileged place in what we learn from other people, this sort of view seems to picture us as perversely preferring to increase our epistemic exposure, by placing ourselves at the mercy of the free disposition of another, according a privileged place to human speech, which is here construed as a kind of evidence that has been deliberately tampered with. On the "evidential" reconstruction of testimony, speech functions as no more than a very possibly misleading way of learning the speaker's beliefs. Other things being equal, some more direct way of learning would be better; and in particular we should prefer any way of learning the speaker's beliefs that was not wholly dependent on his overt, deliberate revelation of them. Anything that necessarily involved his free action

\section{Getting Told and Being Believed}

in this way, and thus brought with it the possibility of deliberate deceit, could only be a less reliable way of learning his beliefs than some otherwise comparable way that involved going behind his back (mind-reading, brain-scans, private observation of his behavior). If speech is seen as a form of evidence, then once its intentional character is recognized (that is, not just as intentional behavior, but intentional with respect to inducing a particular belief), we need an account of how it could count as anything more than doctored evidence.

\section{Assertion as Assurance}

Let us contrast this view with another picture of how what another person tells me may contribute to my belief, a picture that will give central place to the act of saying something and the response of believing or disbelieving the person. On a genuinely non-Humean account, when someone tells me it's cold out, I don't simply gain an awareness of his beliefs; I am also given his assurance that it's cold out. This is something I could not have gained by the private observation of his behavior. When someone gives me his assurance that it's cold out he explicitly assumes a certain responsibility for what I believe. What this provides me with is different in kind, though not necessarily in degree of certainty, from beliefs I might have read off from his behavior, just as what I gain from his declaration of intention differs from the firm expectation I may form from knowing his habits. On the evidential picture, by contrast, the speaker's assurance as such just clouds the issue, since all the verbal expression of assurance can do is interpose an additional piece of (possibly misleading) evidence between me and what I really want to know. I now have some more behavior to interpret, verbal this time, which brings with it special new possibilities for being misled. From my role as interpreter of others, my ul- 


\section{Richard Moran}

timate destination is the truth about the world, but often I must pass through the beliefs of another person as my only (fallible) access to this truth. And now relying on what he deliberately says provides me with at best a distinctively fallible way of learning what his beliefs are.

On both views, when I take someone's word for something I am peculiarly dependent on the will or discretion of the speaker, in a way that I would not be in the situation of interpreting the evidence of his behavior. But they view this dependence differently. On the Assurance View, going behind his back to learn his beliefs would not be better, or even just as good. Rather, it is essential to the distinctive reason for belief that I get from assertion that it proceeds from something freely undertaken by the other person. Only as a free declaration does it have that value for me. Evidence, by contrast, is not dependent on presentation in this way. A phenomenon will count as evidence however it came about, whether by natural causes or by someone's deliberate action, or just as easily by his inadvertence or carelessness. But nothing can count as someone's assurance that was not freely presented as such, just as talking in one's sleep cannot count as making an assertion or a promise. ${ }^{10}$ The two views, then, oppose each other most directly over this issue of the role of the speaker's freedom, and the hearer's dependence on it. On the Evidential View, dependence on the freedom of the other person just saddles us with an additional set of risks; now we have to worry not only about misleading (natural) evidence but deliberate distortion as well. On the

\footnotetext{
${ }^{10}$ When in the course of a discussion of Moore's Paradox and the idea of "two people speaking through my mouth", Wittgenstein asks, "Where is it said in logic that an assertion [Behauptung] cannot be made in a trance?", I understand him roughly to be saying: Logic (on some conception of it) may well say nothing about the speaker's awareness of what he is doing in making an assertion, just as the same conception of logic permits statements of the form 'P, but I don't believe it', but both possibilities are contrary to the point and hence the meaning of assertions (Wittgenstein [1980], § 818).
}

\section{Getting Told and Being Believed}

Assurance View, dependence on someone's freely assuming responsibility for the truth of $\mathrm{P}$, presenting himself as a kind of guarantor, provides me with a characteristic reason to believe, different in kind from anything provided by evidence alone.

In the remainder of this paper, I want to sketch out a defense of the alternative picture above, and explore the case for denying that human testimony should be thought of as providing the same sort of reason for belief that ordinary evidence does. A guiding question will be: as hearers faced with the question of believing what we are told, how are we to understand the nature of our dependence on the free assertion of the speaker, and how does this dependence affect the question of whether our epistemic relation to what is said is ultimately an evidential one?

In a ground-breaking paper on the central questions of testimony, Angus Ross (1986) begins by raising the question of whether it makes sense in general to treat what people say as a form of evidence, and he explicitly relates this question to the fact that speaking is a voluntary act. I have some differences with how he understands this relation, but the general line of thought seems to me deeply right and worth developing. Let me begin with a moderately lengthy quotation from the early pages of Ross's article. ${ }^{11}$

The main problem with the idea that the hearer views the speaker's words as evidence arises from the fact that, unlike the examples of natu-

${ }^{11}$ I should add that I'll only be discussing a part of Ross's argument, focusing on his criticism of an Evidential View of testimony, and not his positive account of how assertion contributes to belief. Michael Welbourne's account of testimony in his monograph The Community of Knowledge has various affinities with Ross's, including the denial that an act of telling is presented by the speaker as evidence, and an emphasis on believing the speaker as the target notion for an understanding of testimony (and the concept of knowledge itself on 


\section{Richard Moran}

ral signs which spring most readily to mind, saying something is a deliberate act under the speaker's conscious control and the hearer is aware that this is the case. The problem is not that of whether the hearer can in these circumstances see the speaker's words as good evidence; it is a question of whether the notion of evidence is appropriate here at all. There is, of course, nothing odd about the idea of deliberately presenting an audience with evidence in order to get them to draw a desired conclusion, as when a photograph is produced in court. But in such a case what is presented is, or is presented as being, evidence independently of the fact of the presenter having chosen to present it. If a speaker's words are evidence of anything, they have that status only because he has chosen to use them. Speaking is not like allowing someone to see you are blushing. The problem is not, however, that the fact of our having chosen to use certain words cannot be evidence for some further conclusion. Our choices can certainly be revealing. The difficulty lies in supposing that the speaker himself sees his choice of words in this light, which in turn makes it difficult to suppose that this is how the hearer is intended to see his choice. (Ross, p. 72)

First of all, it should be noted that Ross's target, like mine, is not the class of all speech-acts, not even the class of all assertoric speech acts. Not everything done in speech, not even everything done with sentences in the declarative mood, involves the specific relations of telling and being believed. Assertions are also made in the context of argument

\section{Getting Told and Being Believed}

and demonstration, for instance, where there is no assumption within the discourse that the speaker is to be believed on his say-so. ${ }^{12}$ In such a situation the speaker is not expecting to be believed but is attempting to provide independent convincing reasons for the truth of his view, or laying out the steps of a proof. Telling someone something is not simply giving expression to what's on your mind, but is making a statement with the understanding that here it is your word that is to be relied on. It is a common enough understanding, and commonly justified, but it is not one in place in such contexts as persuasion, argumentation, or demonstration. For different reasons it is also not the understanding of the speech of a person in the context of therapeutic treatment, in the oral examination of a pupil, or in the police interrogation of a suspect. Such discourses will contain statements of various kinds, but they may be received by the interlocutor in a very different spirit, as evidence for truth of a very different kind from the overt subject of the subject's statement. This again is quite different from the exchange of information through telling and being told in everyday life. (And on the picture of speech to be developed here, these other discourses emerge as ultimately dependent on the central discourse of telling.)

Having said that, however, how is seeing my own utterance as evidence supposed to be incompatible with seeing my utterance as a voluntary act of mine, in Ross's words seeing it as "up to me what I shall say"? He notes that there is nothing in the idea of evidence itself which is inconsistent with a person's deliberately presenting something as such, as when a photograph is introduced as evidence. And, it should also be noted, an item like a photograph can serve as good evidence even when it was not only deliberately pre-

${ }^{12}$ And if we take it that assertions are made in the course of following out a proof, or in ad hominem argument, then it's clear that their role in providing reason for belief needn't even depend on the assumption that the speaker believes what he says. See my paper "Problems of Sincerity" (2005). 


\section{Richard Moran}

sented but also deliberately produced so as to lead one to a particular conclusion. So why cannot the speaker have essentially the same relation to his own words, as something he deliberately produces and presents to serve as evidence for some conclusion (and hence to bring the hearer to some desired belief)? Part of the answer Ross gives lies in the following view. Seeing the utterance as evidence would involve seeing it as the outcome of some general empirical law, the sort of "reliable correlation" Hume has in mind, connecting the making of the statement with the obtaining of the facts in question. Ross acknowledges that I may see the words of others or my own past words in this light, but

What I cannot do is see the words I now choose to utter in that light, for I cannot at one and the same time see it as up to me what I shall say and see my choice [...] as determined or constrained by facts about my own nature. (73)

Such a stance toward one's own utterances may be barely possible, he says, but "it is hardly compatible with taking responsibility for those acts". While the emphasis on responsibility is important, I don't think this part of Ross's response leads in the right direction. For, as far as "reliable correlations" go, why could I not see my own utterance as securely linked with the truth, not in virtue of my being determined by the facts of my own nature, but in virtue of my own free but unswerving commitment to the truth? The sort of reliability my Humean interlocutor wants to count on does not abolish my freedom. I can present myself to myself and others as reliable in various ways, without that meaning that my reliability is a constraint to which I am passively subject. My utterance is a voluntary act of mine, something I take responsibility for, and part of what I take responsibility for is

\section{Getting Told and Being Believed}

its correlation with the truth. So it seems it cannot be because I see my utterance as freely chosen that it cannot be taken by either myself or my audience as evidence for the truth.

However, there is another strand in what Ross is saying here that clarifies the role of the speaker's freedom and its clash with the idea of evidence. In the first passage quoted he says that something like a photograph will be evidence "independently of the fact of the presenter having chosen to present it"; whereas by contrast,

If a speaker's words are evidence of anything, they have that status only because he has chosen to use them.

Strictly speaking, this last statement is not quite right, as we've already briefly seen. If we've agreed that in various contexts a person's words can be treated as evidence, then this need not be dependent on the speaker's having chosen to use them. If my analyst can adopt a symptomatic stance toward my more conscious and deliberate statements, then he may make similar revealing inferences from my botched utterances, slips of the tongue, as well as the words I may utter under hypnosis or while talking in my sleep. Speaking is a form of behavior, after all, and human behavior is infinitely interpretable, infinitely revealing, in ways that are not at the disposal of the person to determine their meaning. One's words can be evidence when not chosen at all, revealing like a cry of pain; or they can be evidence against one's intent, as when someone's tone of voice reveals that he's lying. What is true, however, but still in need of defense here, is that a statement provides the kind of reason for belief that testimony does only if it is understood to be something freely and consciously undertaken by the speaker. It is with respect to 


\section{Richard Moran}

this sort of reason for belief that we, as hearers or readers, are essentially dependent on the free disposal of the speaker or writer. Thus, if the idea is that something is evidence, or is being treated as evidence, when it is a reason for belief independently of whether it was intentionally produced or presented as such, we need a fuller characterization of the kind of "independence" that pertains to the category of evidence, and defense of the idea that testimony as such provides reason for belief that is not independent of assumptions involving the freedom of the speaker.

\section{Photographs and Statements}

It is here that Ross's passing contrast between our epistemic relations to photographs and speakers is worth developing in some detail. There are many ways in which what we see and what we believe may be dependent on what others do, say, or show to us. In my direct experience of a footprint, I may be dependent not only on the person who made it but also perhaps on someone who drew it to my attention. And when my epistemic relation to it is mediated by another person in these ways, I am subject to the ordinary risks of distortion, since in principle any evidence may be tampered with. But even with these particular risks and dependencies, my relation to the footprint is still a perceptual one and does not involve me in the specific relation of believing another person. And this is so even if my perception of it is technologically mediated in ways that involve the doings and expertise of other people. In discussing the nature of photographic realism, Kendall Walton (1984) compares what we see in photographs with what we see through a microscope or in a mirror, to argue for the claim that in all three cases we actually see the thing in question, even though this seeing is mediated in various ways, and even though photographs can be doctored in various ways. ${ }^{13}$ Real experience of a thing

\footnotetext{
${ }^{13}$ For purposes of the account of testimony developed here, we need not of
}

\section{Getting Told and Being Believed}

may also be mediated or subject to various epistemic risks, without that abolishing the difference between being told about it and experiencing it oneself. As Walton points out, what I see directly when someone points out the window may also be altered in various ways to deceive, but that doesn't transform the situation from perception to depiction. In Walton's terms, a photograph can be "transparent" to the scene it depicts in part because, unlike the case of a drawing, what we see here is not essentially dependent on what the photographer thinks is there in the photograph. As with a telescope, we may "see through" the photograph to the scene itself.

In this regard, consider the case of the photographer in Antonioni's movie Blow Up (1966). He takes some pictures in the park of a woman and a man, and then later discovers that one of his shots apparently shows the man's corpse lying in the bushes. This is not what he saw or believed at the time, but it is what he sees now. Still, the photograph he took is evidence, of the most ordinary kind, for the fact that this man has been killed. And it is evidence for this regardless of the photographer's beliefs about the matter. That is, it would be evidence even if he positively disbelieved what it shows, or even if he took the photograph and showed it to someone with the deliberate intent to deceive. Its status as evidence is wholly independent of his beliefs or intentions. And it is for that reason that his own relation to the photograph can be an evidential one, like that of a detective or other investigator. When he gets home he crops and enlarges and studies his photograph in order to see more deeply into what it shows, to convince himself that the corpse on the grass is really there. In this way his own epistemic relation to the photograph he took is the same as that

course follow Walton in his claim that the object itself is in fact seen in the photograph, for it is precisely the differences between photographs and assertions that concern me here. 


\section{Richard Moran}

of the friend he shows it to later. They can both learn from it, or doubt what it shows. The situation would be quite different if he were to have made a sketch of what he saw in the park, or taken some notes on what he observed there. It would be absurd for him take his sketch home and blow up it to examine more closely what it shows about the man in the park. And were he to show his sketch or his notes to another person to convince him about the man in the park, he would be offering him a very different kind of reason to believe what happened. If he shows his friend a sketch of a corpse lying in the grass, and this is to be a reason for him to believe there was such a corpse, his friend has to assume such things as that the sketch was not made with an intent to deceive, that the person who made it was observing things accurately and not liable to error, and even that the aim of the sketch was an accurate picture and not an imaginary scene, etc. In short, the beliefs and intentions of the person who made the sketch are crucial for its status as a reason to believe anything about what was there in the park. Without those assumptions, the sketch does not become poorer evidence; it ceases to be evidence of any kind, or any other reason to believe. It's just a piece of paper, and any correlation with the facts in the park could only be by the merest chance.

So how does the issue of freedom figure in here, in a way that distinguishes the case of verbal testimony? After all, the photographer freely takes his picture, and then may freely present it to another person as a reason for believing a man has been killed. How is this different from his friend's relation to his verbal report of what he saw? So far we have seen the following difference. The status of the photograph as a reason to believe something does not depend on the photographer's own attitude toward it as evidence. It depends only on the camera's ability to record the scene, which

\section{Getting Told and Being Believed}

need not involve any choice or consciousness on the part of the photographer at all. (The exposure could have been made by a remote timing device.) As such the photograph can serve for him as an independent correction of his impression of the scene, in a way that his drawing cannot. It is for this reason that when he looks at his photograph with his friend, they both stand in the same epistemic relation to it; confronting it as independent, public evidence and trying to discern its import.

By contrast, the speaker's choice enters in essentially to the fact that his utterance counts at all as a reason for belief. The point is not that his utterance is voluntarily produced, for that in itself has no epistemic significance and does not distinguish the case from that of the photographer. Rather the point is that the speaker, in presenting his utterance as an assertion, one with the force of telling the audience something, presents himself as accountable for the truth of what he says, and in doing so he offers a kind of guarantee for this truth. This shows up in the fact that if we are inclined to believe what the speaker says, but then learn that he is not, in fact, presenting his utterance as an assertion whose truth he stands behind, then what remains are just words, not a reason to believe anything. We misunderstood the intent of Professor Higgins when we heard him say something about the rain in Spain, and now upon realizing this, the utterance as phenomenon loses the epistemic import we thought it had (whatever knowledge we may indeed take him to have about such matters). By contrast, if we learn that the photographer is not, in fact, presenting his photograph as a true record of what occurred in the park, the photograph as document retains all the epistemic value for us it ever had.

\section{The Importance of Being Non-Natural}

Still, one might ask, why speak of the audience's dependence on the freedom of the speaker, rather than simply refer 


\section{Richard Moran}

to their dependence on what the speaker has (freely) done? The reason is that the relevant speaker's responsibility is not simply his responsibility for the existence of some phenomenon, in the sense that he is the one who deliberately produced these spoken words. Rather, he is more centrally responsible for those words' having any particular epistemic status. What is the difference, then, between the speaker's role in providing something (his utterance) with a particular epistemic status and the role of someone like a photographer who produces something that has a certain epistemic import?

It is here, I think, that a consideration of Paul Grice's original 1957 paper "Meaning" proves helpful. The relation of evidence, one phenomenon's being an indication of something else, is the central form of what Grice calls "natural meaning". Natural meaning is not something at the disposal of the speaker to confer or revoke but is a matter of the independent obtaining of causal relations in the world (e.g, the way smoke means fire, or doesn't). Nonetheless, persons belong to this same natural world and may thus produce or exhibit various evidential phenomena and employ them to get some point across (e.g., pointing to the smoke pouring out of the oven). But spoken words typically bear a different relation to the facts. In his 1957 article, Grice is primarily concerned to delineate the conditions for something he calls "non-natural meaning", or "MeaningNN". This project famously evolved into an attempt to ground the notion of the meaning of an expression in a language in the complex intentions had by utterers of expressions on occasions of use; and, presented as a non-circular account of either wordmeaning or sentence-meaning, it was progressively refined into baroque complexity under the pressure of counterexamples. However, the interest and importance of the original account of non-natural meaning is not exhausted by the prospects for an intention-based semantics of the sort he

\section{Getting Told and Being Believed}

proposed. What he isolates under the title of "non-natural meaning" is a central form of intersubjective dependence, one that is indeed paradigmatically linguistic, but not restricted to linguistic communication.

A striking thing about the essay is how the technical notion of non-natural meaning is introduced by contrast with natural meaning, as if this were an antecedently intuitive notion, one whose definition we could progressively refine by consulting our intuitions about a series of well-crafted cases and asking ourselves whether we should call that a case of non-natural meaning. We are given hints, of course, by way of both similarity and contrast with more familiar notions like that of conventional meaning, but Grice's target notion only emerges through the consideration of the cases devised and presented. The cases themselves all have a similar form in that in all of them one person does something which either succeeds or not in inducing another person to some belief P. This common telos to the cases invites two related questions. Since the end-point of each of these encounters is that one person ends up with a new belief, we might look at the progression of cases from an epistemological point of view and ask what it is that brings the person at the receiving end to this new belief, what reason he may take himself to have been given for adopting it, and why the particular kind of reason Grice's account of non-natural meaning zeros in on should be of special significance, either epistemologically or otherwise. It is not, of course, as if the other ways of inducing belief, disqualified as candidates for the non-natural, are thought to be insufficiently grounded. Salome, for instance, certainly acquired justified belief about the fate of John the Baptist by seeing his head presented on a charger, however this may fall short as a case of non-natural meaning. Rather, the target notion of non-natural meaning is meant to capture a way of gaining a reason to believe 


\section{Richard Moran}

something that is importantly different from others and that we have special reason to be concerned with, both as purveyors and receivers of such reasons. So the first question is: what is special about the reason for belief associated with non-natural meaning? And secondly, as the proposed definition of non-natural meaning is progressively refined in Grice's essay, what pre-theoretical notion is supposed to be guiding our intuitions along the way, so that we can feel conviction about a range of cases that seem to fall more or less squarely in the category? Here Grice is more explicit, since by way of explaining the distinction that matters to him, and why something like the case of Herod's presentation to Salome does not count as non-natural meaning, he says, "What we want to find is the difference between, for example, 'deliberately and openly letting someone know' and 'telling' and between 'getting someone to think' and 'telling'" (44). So it is the ordinary notion of telling someone something, that way of inducing belief, that is to play a guiding role in determining which cases satisfy the philosophical notion of non-natural meaning, and Grice's distinction between natural and non-natural meaning can be seen as motivated by a concern with the difference between telling a person that $\mathrm{P}$ and other ways of bringing him to that same knowledge, such as providing him with evidence for P (evidence that may be accidental or contrived, openly displayed or inadvertently revealed).

As examples of "deliberately and openly letting someone know" some fact, Grice cites such cases as that of showing someone a compromising photograph or "leav[ing] the china my daughter has broke lying around for my wife to see". ${ }^{14}$ In these cases, the phenomenon in question has some independent evidential significance, even though the person may be responsible either for drawing attention to it (the

${ }^{14}$ Grice (1957), in Strawson, ed., p. 44. Ross discusses natural vs. nonnatural meaning at p. 74 .

\section{Getting Told and Being Believed}

broken china) or actually producing it (the photograph). Their independent significance shows up in the fact that the photograph or the china would have functioned as a reason for the belief in question without anyone's intervention or presentation, even if only stumbled upon accidentally. By contrast, in cases of telling or non-natural meaning, the person (hereafter the "speaker") plays quite a different role in bringing his audience to believe something. Here, as is well known, a crucial role is played in Grice's account by the recognition of the speaker's intention. Examining this role will help clarify the specific "dependence on the freedom of the speaker" that I'm claiming is characteristic of the relation of testimony, and which distinguishes it from a relation of evidence.

Following Grice's progression then: a handkerchief left at the scene of the crime may throw suspicion on someone and perhaps lead to genuine belief in his guilt. But as a piece of evidence it would induce that belief whether or not it were left there intentionally, and non-natural meaning (and telling, surely) must at least be the upshot of something intentionally done. Further, it should be part of non-natural meaning that the intention to induce a particular belief is manifest to the person on the receiving end, and not like artfully planted evidence designed to steer him toward the desired conclusion. Further still, this belief-inducing intention must not simply be known to the audience, something he pieces together despite the speaker's best efforts at concealment; rather the speaker must fully expect and intend that his intention will be manifest to his audience. In this way, the audience can appreciate that another person is openly playing a role in directing him to learn something, by presenting a piece of evidence for them both to see and assess. This makes this knowledge, or at least this awareness of the evidence, "mutual" between them and hence available as an object of cognitive and communicative cooperation between 


\section{Richard Moran}

them. However, this is not yet non-natural meaning, since these conditions are fulfilled when Herod presents the head of St. John to Salome, or when the compromising photograph is flourished. Here, although the audience has been directly and openly led to some belief, she has not been told anything. Rather, Salome has been shown something and reliably left to draw her own conclusions. Herod manifests a definite intention in bringing her this news, and he bears an obvious responsibility for Salome's altered state of belief. But there is yet another responsibility he does not assume here, which marks the difference between "'deliberately and openly letting someone know" and "telling", and this is shown in the fact that, while his intention regarding her belief is indeed manifest, it is inert as far as Salome's belief is concerned, just as it is when the person is shown a compromising photograph. It isn't doing any epistemological work of its own. Both people would draw essentially the same conclusions whether the evidence in question were deliberately and openly displayed to them or not. So we might say that Herod's epistemic responsibility for Salome's belief is merely contingent, like that of the person showing the photograph. In these cases they play a role in making a piece of evidence available to another person, but they are not responsible for its having the epistemic import it has.

For Grice, however, nothing can count as a case of nonnatural meaning if the relevant belief could be expected to be produced whether or not the intention behind the action were recognized. The speaker must not only intend that the audience recognize his intention, but this recognition must itself play a role in inducing the belief in question, and that means that the recognition of the speaker's intention must not just as a matter of fact help to bring about the relevant belief but must be necessary to its inducement. In this way we arrive at Grice's original formulation of non-natural
Getting Told and Being Believed

meaning in his 1957 paper:

A uttered $x$ with the intention of inducing a belief by means of the recognition of this intention. (45)

If the audience could not be expected to arrive at the intended belief apart from the recognition of the speaker's intention regarding that belief, the speaker must take upon himself the role of providing something with a particular epistemic import that it otherwise would not have, and in this way Grice sharply distinguishes non-natural meaning from the presentation of evidence. For any phenomenon with some independent evidential import will naturally be one which might well be expected to induce belief without the recognition of anyone's intention. That's just what it is for a phenomenon to be ordinary evidence for something else. If his utterance is to count as an instance of telling someone something, however, the speaker must present his action as being without epistemic significance apart from his explicit assumption of responsibility for that significance. In this way he announces that the reason for belief offered here is of a different kind from that stemming from externally obtaining evidential relations.

As Ross points out (p. 75), from the point of view of the audience the role of the recognition of intention, considered as a reason for belief, is left somewhat mysterious here. The question is: just how does my recognizing that this speaker intends that I should believe P play a role in actually getting me to believe that P? If we compare this case with that of other things someone may want me to do it's clear that the mere recognition that he wants me to do $X$ does not, in general, provide me with much of any reason at all for complying. Why should we be so much more compliant when we 


\section{Richard Moran}

recognize that someone wishes us to believe something? How can the mere recognition of someone's intention be expected to induce belief?

When looked at in this way, recognition of the speaker's intention may seem inadequate to induce belief. It may also seem pointless, adding nothing of epistemic value to what the audience already has. Again, compare this with the picture of radical interpretation, according to which the epistemic significance of speech is that of an indication of the speaker's beliefs. Once I employ this scheme of interpretation to learn what the speaker believes, I am then in possession of knowledge of a certain set of facts, viz., the speaker's state of belief, which does have straightforward evidential value for me, quite independently of how or whether the fact of his believing is explicitly presented to me. The speaker's state of mind is a phenomenon, which has the same independent evidential import for me, regardless of how I may have learned of it, and regardless of whether it was manifested deliberately or inadvertently. And, as we saw, this same scheme of interpretation can provide a basis for me to infer to the likely truth of these beliefs, and so come to share them myself. I ascribe beliefs on the basis of his verbal behavior as I would from any other behavior, and in neither case do I rely on recognition of any intention to manifest his states of mind. And indeed, what could be the epistemic interest for me in learning of any such intention on his part? By hypothesis, I already know what he takes to be true, and I can now make of this knowledge what I will, deciding for myself whether this adds up to good reason for me to take his belief to be true. If his verbal behavior is evidence for his beliefs, then it doesn't add to my evidence as interpreter to learn that, in addition to his believing $\mathrm{P}$, the speaker also has the intention that $I$ should believe $P$ too (and come to this belief on the basis of recognition of that

\section{Getting Told and Being Believed}

very intention, etc.). From my side, either learning of his belief is, on balance, sufficient for me to believe $\mathrm{P}$ too, or it is not. Nothing further about his intentions, or just how he would like me to arrive at this belief, will be evidentially relevant for me at all. Or else, as before with the tainted evidence, learning that his belief was deliberately manifested now casts doubt on my ascription, because the evidence of his behavior is now contaminated by its aspect of performance.

What is needed is more direct focus on the speaker's explicit presentation of himself as providing a reason for belief. For it is not, in fact, the audience's mere awareness of the speaker's intention that is to provide a motivation for belief. If I simply discovered on my own that this person had the intention that I believe $\mathrm{P}$, this need not count for me as a reason for belief at all. (Why cooperate with his designs on me, however benign?) The conditions given so far still have not accounted for any special importance to the overt act of saying, the explicit manifesting of one's intention, as opposed to simply doing something that allows one's intention to become known. If, unlike a piece of evidence, the speaker's words have no independent epistemic value as a phenomenon, then how do they acquire the status of a reason to believe something? It seems that this can only be by virtue of the speaker's there and then explicitly presenting his utterance as a reason to believe, with this presentation being accomplished in the act of assertion itself. The epistemic value of his words is something publicly conferred on them by the speaker, by presenting his utterance as an assertion. And indeed, it is because the speaker's words have no independent status as evidence that their contribution to the audience's belief must proceed through the recognition of the speaker's intention. Further, the intention seeking recognition must not simply be that the audience come to believe 


\section{Richard Moran}

something, but must include the intention that the audience recognize the speaker's act of asserting as itself constituting a reason for belief. If it seems difficult to see how anything, even someone's words, could acquire some epistemic value through something like conferral, perhaps because this suggests something too arbitrary or ceremonial to constitute a genuine reason for belief, it should be remembered that for both parties this conferral is by its nature an overt assumption of specific responsibilities on the part of the speaker. This is no more (or less) mysterious than how an explicit agreement or contract alters one's responsibilities, actions which are also within the capacities of ordinary speakers. The speaker's intent, then, is that for the audience, the very fact that this speaker is freely and explicitly presenting $\mathrm{P}$ as worthy of belief constitutes his speech as a reason to believe that $P$.

Of course, as with any public assumption of responsibility, the appropriate abilities and other background conditions must be assumed to be in place for it to amount to anything. For the speaker to be able to do this it must be assumed by both parties that the speaker does indeed satisfy the right conditions for such an act (e.g., that he possesses the relevant knowledge, trustworthiness, and reliability). These background conditions can themselves be construed as evidential, or at any rate not at the behest of the speaker to determine, but they are not themselves sufficient for giving any epistemic significance to the speaker's words, for the relevance of these conditions only comes into play once it is understood that a particular speech-act is being performed with those words (i.e., an assertion or promise rather than something else). The speaker has to constitute his utterance as having this or that illocutionary force before the empirical background conditions can contribute anything to its epistemic significance. Hence the idea is not that the speaker's

\section{Getting Told and Being Believed}

word's "all by themselves" should count as a reason for belief, or that the speaker's authority over the constitution of the particular speech act he is performing (e.g., as assertion rather than recitation) shoulders the epistemic burden all by itself. As with the explicit assumption of responsibility that goes with making a promise, its success will depend on the various conditions that go into the speaker's being in a position to take on any such responsibility, and which make for his public assumption's being anything for another person to count on. But in considering the speaker's words, the audience's belief in his knowledge and trustworthiness do not do him any epistemic good if it is still left open just what kind of action (if any) the speaker is presenting his utterance as. As far as relating to his words goes, the speaker's knowledge and trustworthiness are epistemically inert for the audience until the question of the particular speech-act or illocution is settled. Determining his utterance as an assertion is what gets the speaker's words into the realm of epistemic assessment in the first place (or at least epistemic assessment of the sort that is relevant to testimony: we may indeed make evidential use of the words or inarticulate sounds made by someone asleep). And in this matter, the speaker and his audience are in essentially different relations to the epistemic import of the speaker's words. The speaker does not relate to the question whether his utterance is a committed assertion or not as something to be settled by evidence, because as a speaker of the language he plays an essential role in making it the case that his utterance is an assertion or not.

Hence Grice's original formulation needs some further refinement. The speaker intends not just that the recognition of his intention play a role in producing belief that $\mathrm{P}$, but that the particular role this recognition should play is that of showing the speaker to be assuming responsibility for the status of his utterance as a reason to believe P. This addition 


\section{Richard Moran}

is necessary since in principle there are all sorts of ways in which the recognition of intention could "play a role" in producing belief, ways that would not capture what is meant by "telling" or "non-natural meaning", or the correlative notion of believing the speaker. One such way would be manifested in the familiar situations of "double-bluffing" where, e.g., I tell you I'm traveling to Minsk, knowing you'll take me to be lying and attempting to conceal my plans to travel to Pinsk, and hence meaning to deceive you about my genuine plans to go to Minsk after all. Knowing all this about me, however, you see through the ruse and conclude that I'm indeed going to Minsk, just as I told you. Here the recognition of intention does indeed play an essential role in the belief arrived at, and the audience comes to believe that what I say is true, but this is not a case of believing the speaker. ${ }^{15}$ And there are other possible ways in which the recognition of intention might play a role, even a necessary one, but of the wrong sort.

Grice is sensitive to an incompleteness here, when he suggests toward the end that it should somehow be built into the definition that "the intended effect must be something which in some sense is within the control of the audience, or that in some sense of 'reason' the recognition of intention behind $\mathrm{X}$ is for the audience a reason and not merely a cause" (46). It is not the speaker's aim that the belief in question be produced by the audience's simply being so constituted that his awareness of the speaker's complex selfreferential intention somehow produces the belief in him. That would fail in another way to describe the nature of the dependence on the person as such and the importance of mutual recognition. For the audience must not simply re-

\footnotetext{
15 At the end of her (1979) paper, Anscombe points out that it is a requirement of any successful account of the phenomenon that it explain why we only speak of believing someone when we take them to be both right about the facts and truthful in intent.
}

\section{Getting Told and Being Believed}

spond with belief but must understand what the speaker is saying, and must understand what the speaker is doing in saying $\mathrm{P}$, which is to say, purporting to present him with a reason for $\mathrm{P}$. And the audience must believe $\mathrm{P}$ because he understands what the speaker is saying and what he is doing in saying it. In addition, and crucially, the audience must take this entire understanding to be shared by himself and the speaker. That is, he takes himself to be responding to just the kind of reason for belief that the speaker is presenting himself as offering (which is why cases of "doublebluffing" are not cases of believing the speaker).

Any of the "proto-Gricean" ways of producing belief, the cases leading up to the full definition of non-natural meaning, provide us with something mediating between the audience and the speaker, something other than the person as such that is being depended on. Believing the speaker, on the other hand, involves accepting the offer to rely on him and not something connected with him or as a consequence of what he has done. This direct dependence on the speaker's offer of responsibility is what is expressed in the 'hereby' that is implied, and sometimes explicitly stated, in illocutions such as telling, warning, or accepting, for it is in this very presentation of himself that the speaker assumes responsibility for the audience's belief. ${ }^{16}$ The implied 'hereby' is thus also an expression of the self-referentiality of the Gricean formula, for it declares that it is dependence on the person as such, and not on something else he might point to, that is solicited in saying that he hereby tells his audience that $\mathrm{P} .{ }^{17}$ In this way we can see the progressive re-

${ }^{16}$ Austin (1962), p. 57.

${ }^{17}$ Here I agree with Harman (1986) in seeing as mistaken Grice's later attempts to eliminate the self-referentiality in his original formulation for nonnatural meaning: "Much of this complexity is artificial and due to Grice's refusal to stick with the original analysis and its appeal to a self-referential intention" (p. 88). 


\section{Richard Moran}

finements of Grice's definition of non-natural meaning as each aimed at laying bare the reliance of the audience on the other person as such. The belief is to be produced not simply by the speaker's action, or by his intention, or by the audience's awareness of his intention, or anything else outside their encounter. Just as the audience could treat the handkerchief or the photograph as evidence for $\mathrm{P}$, and thus without trusting the speaker for the truth of $\mathrm{P}$, so he could treat the speaker's action or intention as a similar kind of evidence without trusting the speaker, without his belief that $\mathrm{P}$ involving dependence on the person of the speaker as such.

When Grice says that the belief in question should be "something which in some sense is within the control of the audience", or that it should function as a reason for him and not a mere cause, this is not meant to suggest that the audience complies with the speaker's intention as a kind of favor, adopting the belief on request (as Ross notes, p. 74). But it does serve to clarify the kind of role that is to be played by the mutual recognition of the speaker's intention, how that can matter epistemically to the audience in the way suggested by Grice's progressive refinements of the account of non-natural meaning. The account of this role suggested by the Assurance View is that the mutual recognition of intention can play the role for the audience of providing him with a reason for belief, because he sees the speaker as presenting himself as accountable for the truth of $\mathrm{P}$, and asking, through the recognition of his intention, that this offer of his assurance be accepted. And it is understood by both parties that this acceptance is something which the audience is free to give or refuse. The speaker is asking that a certain authority of his be acknowledged-the authority to invest his utterance with a particular epistemic import-and this investment occurs by his explicit assumption of responsibil-

\section{Getting Told and Being Believed}

ity for his utterance's being a reason for belief. This is the role for the recognition of intention that the speaker is asking for. And, I would argue, it is only such a role that could account for how, in the case of speech, the recognition of intention enhances rather than detracts from the epistemic status of the phenomenon (utterance), reveals it to be something other than doctored evidence.

The idea of assertion as providing reason for belief through the explicit assumption of responsibility for the truth of what is said accounts for a number of contrasts between belief through testimony and belief through confronting evidence. It points the way to understanding how the recognition of intention can play a positive role, rather than seeing it as something that is either epistemically irrelevant or undermining to the evidential value of the utterance. Further, a specific assumption of responsibilities is essentially an expression of a person's freedom, something that only makes sense as consciously assumed. It is for this reason that words spoken during sleep or under hypnosis do not have the value of testimony, because they do not count as assertions, whatever expressive psychological value they might still retain as evidence. Like a promise or an apology, something only counts as a person's assertion when consciously presented as such by him. ${ }^{18}$

Promises and apologies, like acts of telling someone something, can be more or less reflective, more or less delib-

${ }^{18}$ Coady (45-46) distinguishes genuine testimony from the situation of someone who has been hypnotized specifically to say something, perhaps even with the expectation of being believed. But his reason for excluding this case is different from mine. For Coady, this cannot count as "testifying" because it fails to satisfy the condition that the speaker "has the relevant competence authority, or credentials to state truly that P" $(42)$, since the words have more or less been "planted" in the subject. This focus on epistemic authority seems misplaced, however. For the speaker in this case could after all also happen to have the requisite competence and authority on the subject. Instead, the reason this doesn't count as testimony is that, in his present condition, he is not presenting 


\section{Richard Moran}

erate, done more or less voluntarily or under duress. Reference to the speaker's assumption of responsibility for the truth of what he says is not meant to deny that much of our speech is spontaneous and unreflective, or that much of what we acquire from the speech of others is more or less passively absorbed. Telling also includes telling something by mistake, to the wrong person, or just blurting something out when we meant to keep silent. We express our freedom not only in our considered actions but also in the actions that go wrong or are forced upon us, and the outbursts that we immediately regret. Blurting something out when you meant to keep silent is still a different matter from either talking in one's sleep or having the utterance of those words be produced by electrical stimulation of the cortex. And the epistemic significance for the audience is entirely different in the two kinds of cases: in relating to the words produced by electrical stimulation we may learn something, but what we learn need not be dependent on such assumptions as, e.g., whether the person had any understanding of the words themselves, or any sense that he was providing anyone with a reason to believe something. These assumptions, however, are still indispensable to the understanding of the words that escape us or are forced from us, and they express the role of the person as such in providing a reason. This is confirmed by the fact that both speaker and audience relate to the blurting out differently than they would to the cases of talking in one's sleep or through electrical stimulation. In the latter case, the speaker would not regret what he said or try to make amends; in a sense what happened didn't involve him at all. ${ }^{19}$ And for that matter, a person may also lie

${ }^{19}$ Holton (1994) provides an illuminating focus on the role of what Strawson refers to as the Participant Stance and the Reactive Attitudes, especially with regard to the distinction between belief through trust and belief through reliance. Holton says of the latter case, "Seen in this way, a person is like a measuring device: they respond to the environment in various ways, and we infer from their response to what the environment is like" (74).

\section{Getting Told and Being Believed}

spontaneously or out of panic as well as tell the truth. But surely the description of a person telling a lie makes reference to such things as the intention, whether conscious or not, to exploit the trust of his audience and present himself as providing them with a reason for belief. At the same time, it is consistent with the Assurance View to think of assertions and tellings as something like the default assumption for indicative sentences in the declarative mood. It requires more, rather than less, sophisticated intentions to utter 'The rain in Spain falls mainly on the plain' and not mean it as an assertion. And so, barring any special reason to think otherwise, we may be entitled to treat an utterance of an indicative sentence as an assertion of it. ${ }^{20}$ But in a given case we may be wrong about this, and it remains true that what settles the question about the status of the utterance is whether or not the speaker is presenting it as true.

\section{The Speaker's Conferral: Having Your Say, Giving Your Word}

We are now in a position to clarify the problem Ross suggested with the idea of a speaker's presenting his utterance as evidence for his audience. The problem is not that the speaker's words could not be taken as evidence by his audience. In principle, anything said or done by the speaker can be given a symptomatic reading. Nor is it true that the speaker could not privately intend that his words be taken as evidence. This would be the intention for many cases of deceit or more everyday manipulation, for instance. In a given case, my primary aim may be for my listener to draw the conclusion that I'm being scrupulously candid or selfrevealing, and I accomplish this by confessing some minor fault of mine. Here, I am not telling anyone of my candor, giving my word on it (whatever good that would do), but

${ }^{20}$ Something like this assumption is expressed in Bernard Williams' idea of assertion as the "direct expression" of one's belief (Williams [2002], p. 74 et 19 passim), which I discuss in Moran (2005), pp. 347-50. 


\section{Richard Moran}

rather doing something (in this case: saying something) that I hope will be taken as evidence for it. When it is a question of non-natural meaning, by contrast, the speaker is not relying on evidential relations alone to get his point across, but rather is counting on the explicit presentation of his intention to be the very thing which makes his words a reason for believing something in the first place. The recognition of his intention could only function this way if it was seen to be his assurance of the truth in question, his explicit assumption of responsibility for the truth of what he says. By contrast, the presentation of his utterance as evidence would be an implicit denial of this responsibility, breaking the link between the proposition he is giving his backing to and the belief he is hoping to induce, in which case there's no question of believing him. Thus, for the speaker to present his word as evidence would be for him to present it as a reason to believe, while suspending the guarantee that gives it the epistemic significance of testimony in the first place. This is the problem Ross is pointing to. ${ }^{21}$

And as we have seen, to present something as evidence is to present it as having its epistemic value independent of one's own beliefs about it, or one's presentation of it, or the conferral of some status upon it. To offer some phenomenon as evidence is to present it as belief-worthy independently of the fact of one's presenting it as belief-worthy. When we present something as evidence for someone, we are inviting that person to "see for himself", to find it convincing as we

${ }^{21}$ Ross, p. 79: "No abandonment of the agent's perspective, no abdication of responsibility for one's actions, is involved in seeing those actions as generating entitlements and obligations, either on the part of ourselves or on the part of others. (Compare the case of promising or issuing a command.) There is on the present account no difficulty in seeing the hearer as taking the speaker's words in the spirit in which they are honestly offered."

See also Robert Brandom's richly developed account of assertion in terms of the constellation of entitlements and obligations, in Chapter 3 of Making It Explicit.

\section{Getting Told and Being Believed}

do. And we are prepared to offer reasons why it should be convincing, reasons independent of our simply claiming, once again, that it is belief-worthy. To present something as evidence is to be in a position to report that it is a reason for belief, and to be in this position one must be presenting that claim of belief-worthiness as having a basis in fact that is independent of one's reporting itself. A photograph has such an independent epistemic basis, independent of anyone's conferral. As a phenomenon, it counts as a reason for belief independently of anything concerning how the photographer may conceive it or present it. Because of this independence, its epistemic status is something the photographer himself may discover about it, or speculate about. His relation to this question is in principle no different from anyone else's. He may, of course, happen to know something about how it was produced that we don't know, and which may affect its epistemic status. But he may not know anything of the sort, and conversely we might know more about it than he does. He marshals the same kinds of reasons as any other viewer in considering the question of what beliefs the photograph may provide a basis for.

But the speaker's relation to the epistemic status of his own assertion is different from anyone else's. For the speaker, it is not a matter of observation or speculation whether he is indeed presenting his utterance as something with the force of a committed assertion, and were he somehow unclear about this, then to that degree his utterance would be something less than a committed assertion. $\mathrm{He}$ may inquire into his own reliability, truthfulness, and command of the facts, but the status of his utterance as assertion is a matter of what he is then and there prepared to invest it with. It has been noted by more than one philosopher that the relation of 'believing someone' does not have a reflexive 


\section{Richard Moran}

form; it is not a relation a person can bear to himself. ${ }^{22}$ The problem with this, we can now say, is the problem with the idea of a person offering and accepting an epistemic guarantee from himself, which would require him to be simultaneously in command of and at the mercy of his own freedom. This is another basic feature of testimony not captured by an evidential perspective on it. Speaker and audience do not confront the utterance as a phenomenon with an independent or natural epistemic status which they could assess in the same spirit, for the speaker does not confront his own assertion as a phenomenon at all, but as an issue of his commitment. To speak of "conferral" of epistemic status is intended to register the fact that to count an utterance as, e.g., an assurance or a promise just is to count it as something presented with a particular epistemic status, the status of a reason for some belief (as contrasted with the status, say, of recitation or ironic mimicry). To count as a competent speaker of a language is to be recognized as having definitive "say" over which illocution one's utterance counts as, whether as informative assertion, or as promise or apology, whether as a mere recitation or as a claim expressing one's commitment. An utterance counts as an assertion or an apology just in case the speaker presents it as such to his audience, in the appropriate context where his audience can be expected to recognize what is being offered. The speaker cannot count as having promised or asserted something if he had no such intention, or if he did not present his utterance to be seen as a promise or assertion, whereas the evidential import of what he says and does is independent of such

${ }^{22}$ After a "preamble", Anscombe begins her essay with the statement "Believe' with personal object cannot be reflexive" (op. cit., p. 144). See also Cavell (1979), p. 393: "A striking exception to the thought that I can stand in any relation to myself that I can stand to others is that of belief. Why apparently can I not, in grammar, believe myself?" conditions.

The speaker's authority to determine the illocutionary status of his utterance is the authority he has to present himself as accountable for the performance of some speech act. This is not a matter of discovery for the speaker, something he could investigate or report on, as he might with respect to the evidential status of something. When it is a question of the evidential status of something, even something the person himself has done, he and his interlocutors are on an equal footing with respect to establishing its standing as a reason for belief. A person does not speak with any special authority about the evidential significance of his actions, including his verbal ones. By contrast, the authority to present oneself as "hereby" assuming certain responsibilities in speech makes the speaker's epistemic position irreducibly different from that of his audience. For him the import of his words is not an independently obtaining fact, something he has his own opinion about, but is directly dependent on the import he is then and there prepared to invest them with. And it is internal to the notion of the speaker's authority to confer illocutionary status on his utterance that he also has the exclusive authority to cancel or revoke such status. Words can be retracted, apologies or warnings taken back, but only by the speaker himself. At the same time, he has no authority to determine, much less cancel, the evidential import of anything he has said or done, not even of his retraction itself.

When all goes well in testimony, a speaker gives his audience a reason to believe something, but unlike other ways of influencing the beliefs of others, in this case the reason the audience is provided is seen by both parties as dependent on the speaker's making himself accountable, conferring a right of complaint on his audience should his claim be false. Whether this counts as a good or sufficient reason 


\section{Richard Moran}

for belief is not a matter of the speaker's illocutionary authority, but will depend both on his sincerity and on his having discharged his epistemic responsibilities with respect to the belief in question. ${ }^{23}$ But his presentation of his utterance as having this particular illocutionary force is what makes it a candidate for epistemic assessment in the first place and determines what kind of reason for just what proposition his audience is being presented with.

This way of looking at testimony makes much of the fact that in its central instances speech is an action addressed to another person, and that in testimony in particular the kind of reason for belief that is presented is one that functions in part by binding speaker and audience together, and altering the normative relationship between them. It doesn't follow from this, however, that someone outside that normative relationship can't avail himself of it and thereby acquire a reason to believe the same thing. If one person gives his word on something to another, whether as promise or assertion, someone overhearing this may derive a sufficient reason to believe, say, that the speaker will in fact do what he promised or that what he asserted is true. And the overhearer improves his epistemic situation in this way without entering into the altered normative relationship of the two parties involved in giving and accepting of words. He has not himself been told anything, much less promised anything, and no right of complaint has been conferred upon him. ${ }^{24}$ To say this much, however, does not provide a reason

\footnotetext{
${ }^{23}$ Cf. Williamson (1996): "To make an assertion is to confer a responsibility (on oneself) for the truth of its content; to satisfy the rule of assertion, by having the requisite knowledge, is to discharge that responsibility, by epistemically ensuring the truth of the content. Our possession of such speech acts is no more surprising than the fact that we have a use for relations of responsibility."

${ }^{24}$ For further discussion of assertions and promises, emphasizing their differences as well as similarities in their relations to the speaker's responsibilities, see Watson (2004).
}

\section{Getting Told and Being Believed}

to assimilate his situation to that of someone confronting a piece of evidence, or to suggest that the speaker's illocutionary and epistemic responsibilities aren't playing a genuinely epistemic role here. For even though the statement was not addressed to him, the overhearer is still in a different position from that of someone confronting a piece of evidence like a photograph or a footprint. It still makes a difference to his epistemic relation to the overheard report that he is responding to something whose epistemic significance is not independent in the way of a photograph or footprint, but is inherited from the speaker's assuming responsibility for the truth (and meaning) of what he says. This is so even if, as we might say, that responsibility was undertaken with respect to another person and not himself.

Naturally there is a certain vagueness as to just what situations will count as overhearing, and in a given case the addressee may be a group of people. Nonetheless, while the overhearer may get a reason to believe without having the right to complaint that is conferred on the addressee, the fact that the overhearer of the assertion acquires any reason to believe from listening to these words is dependent on their being addressed to someone, with the force of assuming responsibility and thereby conferring a right of complaint. The overhearer of testimony is not in the same normative relation to the speaker as the addressee is, but his gaining any reason to believe is dependent on such a conferral having been given to someone. Without that, the question of what speech act, if any, is being performed with these words would not be settled, and hence the overhearer could not get started on assessing their epistemic significance. (Imagine overhearing someone say "The rain in Spain falls mainly on the plain". Until you know what speech act, if any, is being performed here, you don't know if considerations of reliability or trustworthiness are even relevant to the status of 


\section{Richard Moran}

the words as a source of knowledge about the weather in Spain.) So, while in both cases (promising and telling) the overhearer can gain a reason to believe something without entering into the normative relation of promisor-promisee or teller-believer, in the overhearing of testimony he gains a reason to believe something only because such a relationship has been established by the original speaker and addressee.

This, then, is how I suggest we understand Ross's claim that the Evidential View is inconsistent with the kind of reason for belief offered in everyday human testimony. In telling his audience something the speaker does not present his utterance as something with the force of evidence because that would be to present his words as having their specific epistemic import apart from his assurance, and the responsibility he thereby assumes. And in obscuring the speaker's responsibility, such a stance would also obscure the nature of the audience's dependence on him. For if it were a matter of evidence then in principle we would both be on an equal footing with respect to establishing its epistemic import. But this equity does not obtain with respect to someone's words, where it is up to the speaker alone to determine whether they are to count as an assertion or other committed speech act.

\section{Evidence and Disharmony}

The two broad views about testimony which I've been calling the Evidential View and the Assurance View are in no disagreement over the status of an assertion or a promise as essentially the action of a free agent. Both views are clear that speaking is a voluntary activity, and that the speech of others has that kind of significance in our lives. Where they differ is in how that freedom is related to the status of the utterance as a reason to believe. For on the Assurance View, it is not just that a particular free action is seen to have some

\section{Getting Told and Being Believed}

epistemic import, but rather that the epistemic import of what he does is dependent on the speaker's attitude toward his utterance and presentation of it in a certain spirit, whereas by contrast, it is in the nature of genuinely evidential relations that they are not subject to anyone's conferral or revocation. It might still be asked, however, whether it doesn't still all come down to evidential relations in the end. The following reconstruction may be offered. Yes, the speaker freely assumes responsibility for the truth of what he asserts. But now this very act of assurance is a fact, which the audience confronts as evidence (of some degree of strength) for the truth of what has been asserted. Speech is acknowledged to be importantly different from other (indicatively) expressive behavior, but the audience's relation to it, as a reason to believe something, can only be evidential.

The claim of the Assurance View, however, is not that an assertion could not be treated purely as evidence. It is always possible to treat anything a person says or does as constituting further evidence for one thing or another, and there is no level at which this somehow becomes impossible. The point instead is that refusing to acknowledge any epistemic stance toward the speaker's words other than as evidence means that speaker and audience must always be in disharmony with each other, for in the contexts of telling, promising, and apologizing the speaker is not presenting his utterance as evidence. And it is internal to the speech acts of, e.g., telling or thanking that they are not presented as evidence for one's belief or gratitude. To present one's utterance as evidence would be to do something other than to tell, promise, or apologize.

This claim may seem paradoxical. On the Assurance View, the making of an assertion can be treated as evidence, can properly be evidence for various things, but the practice cannot coherently be described as the offering of evidence. 


\section{Richard Moran}

But how could this be? If the speaker recognizes that his asserting can be, or even just is, evidence for the truth of the very proposition asserted, then how could there be anything amiss with his presenting it as something (viz., evidence) that he sees it legitimately is? But this general possibility for self-defeat should not be surprising. To allay the sense of paradox here, compare the assurance given in a promise with that of an assertion, and consider the incoherence or selfdefeat in saying something like 'I promise; but of course I might change my mind, or forget, or cease caring'. Here as well, the speaker is only saying something that both parties know to be true, about himself and about promises in general. But to say so is, at the very least, contrary to the spirit in which a promise is made, contrary to the very point of making a promise. And what makes for this self-defeat is precisely the presentation of it in an evidential spirit. For notice: for someone to say 'I promise, but I might change my mind' is to refer to his promise as a fallible indication of future performance. That is, it is to present it as a kind of defeasible evidence for what he will do. And, of course, insofar as a promise is seen as evidence at all it can only be seen as defeasible evidence. Hence for the speaker to offer his promise as evidence means he must be offering it as, at best, defeasible evidence, with respect to which the promissee is on his own. And to do so is contrary to the point of making a promise, which is assurance.

The disharmony between speaker and audience entailed by the Evidential View comes out in the consideration of two possible responses to receiving a promise. If someone promises to mail a letter for me, one thing I might do is accept his promise, placing myself in his hands and taking myself to now have sufficient reason for believing that he will mail the letter. If it turns out he doesn't mail the letter, either through carelessness or because he never really intended to,

\section{Getting Told and Being Believed}

then I will feel aggrieved and let down. This is the ordinary expectation and liability to disappointment. I might, however, opt for another kind of response altogether. Here I don't accept the promise; I simply don't go in for that sort of thing, as I may not accept promises from a small child or (for different reasons) from someone I despise, but in another way I do take seriously the fact that he made one to me. In this spirit I may reason: "He is unlikely to make a promise he won't fulfill, since that would discredit him as a future promisor, and there are great and obvious advantages in remaining someone whose promises are accepted. Therefore, the fact that he made this promise to me makes it probable that he will in fact mail the letter. So I believe he will." If, on this second scenario, I later discover that he did not mail the letter after all, my reaction will be different. I will be disappointed, of course, and I will be surprised that he would discredit himself in this way. But I can't confront him with my complaint or my resentment because I never accepted the promise in the first place. My relation to this person's promise is similar to my relation to the person I suspect of "double-bluffing" me. I don't believe him; there's no question of that. But nonetheless his statement that he's traveling to Minsk functions as my reason for believing that this is what he will do. In both cases the speaker has made me a free declaration which I then make evidential use of to infer to the truth of what he says. On the Evidential View, this second type of response to promises and assertions would have to be the only epistemically legitimate one, and yet such a reconstruction would yield an incoherent description of the practices of telling or promising. It would be incoherent because on such a view the speaker would have to be in the position of offering assurances that are never accepted, and which he knows are never accepted, and the audience would nonetheless be relying on the continued of- 


\section{Richard Moran}

fering of such free assurances to serve as his evidential base.

The issue of harmony between speaker and audience goes deeper than this, however, and helps to delineate the relationship between the speaker's authority to determine the illocutionary status of his utterance and its actual epistemic import. In asserting that $\mathrm{P}$, where the context is one of telling, the speaker is not in a position to constitute his utterance as a good or sufficient reason for $\mathrm{P}$, since that will depend on his credentials and success as a knower, as well as his honesty. But in the act of telling his audience that $\mathrm{P}$, he does claim definitive "say" in determining that his utterance is being presented as a reason for belief rather than, say, as a speculation or grammatical example, as well as determining just what it is that he is giving his word on. From the speaker's perspective both determinations matter to the alignment of speaker and audience that he sees himself as aiming at. From a purely evidential perspective, however, it shouldn't matter to the audience whether the route from the speaker's words to a true belief involves the loop in doublebluffing or not. And just as clearly in such a case there would be failure of correspondence between the spirit in which the statement is made and that in which it is received. The speaker who asserts $\mathrm{P}$ is not indifferent to whether he induces belief in his audience through the loop of doublebluffing. His assertion is asking for belief in the very proposition stated and for the very sort of reason that he is then and there presenting. And that sort of reason is bound up with his presenting himself as accountable for this truth. In double-bluffing, the reason for belief taken by the audience is different from the reason the speaker offers. What telling aims at, by contrast, is that there be a correspondence or identity between the reason the speaker takes himself to be offering and what the audience accepts as a reason. So we might say, in telling his audience that $\mathrm{P}$, the speaker asks

\section{Getting Told and Being Believed}

that his authority be acknowledged to determine what sort of candidate reason for what belief is up for consideration. This is the spirit in which his statement is made, and it is this that is denied by treating his utterance in a wholly evidential spirit, in which the question of what is being considered a reason for what is anybody's business, and is not tethered to the speaker's awareness or intent. Conversation may of course move into and out of this dimension of assessment, but for purposes of either agreement or disagreement it cannot begin there.

In the speech-act of telling, the speaker commits himself to his audience with respect to a particular proposition, and with respect to the kind of reason being presented. This follows from the difference between doing something that has a certain epistemic significance (as with taking or showing a photograph) and being responsible for something's having the epistemic significance that it has (as with a speaker and his words). In telling his audience something, the speaker aims at being believed, an aim which is manifest to both parties and which binds the speaker and audience together with respect to a norm of correspondence between the reason offered and the reason accepted. When an act of telling completes itself, speaker and audience are aligned in this way through their mutual recognition of the speaker's role in determining the kind of reason for belief that is up for acceptance, so that when the speaker is believed there is a non-accidental relation between the reason presented and the reason accepted. The speaker says, in effect, "The kind of reason for belief you gain from my statement is precisely the kind of reason for belief I am hereby presenting myself as offering you. Insofar as there is a disparity between the two, I disavow responsibility for whatever belief you may derive from my assertion." Presenting his utterance that 


\section{Richard Moran}

way is a kind of declaration of transparency to his audience: the kind of reason overtly presented is precisely the reason that is meant to count for you. When the background of the speaker's knowledge and sincerity can be assumed, and the speaker is in fact believed by his audience (a common enough occurrence, after all), the two parties are in sync with each other in a way that they would not be if the audience were to take the utterance either as a reason for some other belief rather than the one stated, or a different kind of reason for that belief (as with double-bluffing). Taking the utterance as evidence detaches the reason-giving significance of the utterance from the speaker's authority to determine what he is thereby committing himself to. ${ }^{25}$ From an evidential perspective it may function as evidence for any number of things, for which the speaker's competence or responsibility may be irrelevant. This is manifestly not the speaker's perspective on the epistemic significance of his statement, which he sees in terms of the nexus of a specific responsibility assumed and a specific entitlement con-

${ }^{25}$ That the directness of the audience's dependence on the person of the speaker as such is related to the directness of the speaker's own relation to the reasons on which he bases his belief is something I have been helped to see by Adam Leite's paper "On Justifying and Being Justified" (2004). Because the speaker's statement of his reasons is not a hypothesis he makes about the origin of his belief, his assertion makes him (and not, e.g., something inside him) directly accountable for the truth or believability of his claim. Leite puts it the following way (pp. 227 - 228): "Suppose that you consider reasons for and against a claim, find that certain reasons decisively support holding it, and sincerely declare that you believe the claim for those reasons. In the usual case, you thereby directly determine what the reasons are for which you hold the belief. Moreover, in declaring your reasons you both open yourself to epistemic evaluation or criticism on account of those reasons' inadequacy and incur certain obligations - in particular, an obligation either to give up the belief or to seek better reasons, should those reasons prove inadequate. A minimal adequacy condition for an account of the epistemic basing relation is thus that it allow (1) that the reasons for which a belief is held can be directly determined in this way, and (2) that one sometimes directly opens oneself to epistemic criticism and incurs further justificatory responsibilities by sincerely declaring that one holds one's belief for particular reasons."

\section{Getting Told and Being Believed}

ferred. ${ }^{26}$

For the act of telling to complete itself there must be a correspondence between the reason being presented by the speaker and the reason accepted by his audience. This is the nexus that is aimed at in the self-reflexive aspect of the Gricean formula, wherein the speaker asks that the very reason he is thereby presenting be the reason that the audience thereby accepts (i.e., through recognizing that very intention). Telling aims at being believed, which proceeds, via the speaker's overt assumption of responsibility, by joining together the particular belief proposed for acceptance, the kind of reason being presented for it, and the reason accepted by the audience. An evidential stance, by contrast, de-couples all of these from each other, to be re-assembled as the observer thinks best. But such a stance is contrary to the speaker's perspective on his action, insofar as it pictures his presentation of himself as meaning, in effect, that as far as reason-giving force goes, the audience is on his own; as if the meaning of his utterance were "Now I have spoken; make of it what you will" rather than "Take it from me".

More is conveyed in our ordinary assertions than the specific proposition asserted, and more is often intended to be conveyed by the speaker, and much of this will be picked up in an evidential spirit. All of which is to say that not all, not nearly all, speech takes the form of one person telling something to another, testifying to its truth. Not everything

${ }^{26}$ Putting it this way describes the relationship of speaker and audience in terms of an essentially correlative or "bi-polar" normativity, of the sort that has recently been explored by a number of philosophers. By contrast, the nonpersonal nature of evidence, the independence of its epistemic force from its being presented as a reason to another person, expresses the "monadic" character of its normativity. It was only at a late stage of working on this paper that I began to see the direct relevance to these issues concerning testimony of the work on "correlativity", "bi-polar normativity", and private law by Ernest Weinrib (1995), Martin Stone (1996 and 2001), and Michael Thompson (2004); as well as Stephen Darwall's forthcoming work on the second-person standpoint, 26 


\section{Richard Moran}

we need to convey is best conveyed by being told to another, in part because not everything we need to communicate is something we could sensibly ask to be relied on for, present ourselves as accountable for, or ask to be accepted on our say-so (e.g., the occasional comedy or tragedy in someone's asserting his own dignity or probity). Nonetheless, it is clear enough what Anscombe means when she speaks of the insult and injury in not being believed. ${ }^{27}$ And the offence remains even when the speaker's audience takes his having made the statement to count as evidence for its truth, just as above he may take the speaker's having made the promise to make it more probable that he will do the thing in question. The offence lies in his refusing to accept what the speaker freely and explicitly offers him, in favor of privately attending to what the speaker's action passively reveals, just as someone might refuse an apology while still taking it in this case to be a reliable indication of remorse. What makes sense of such refusals is the fact that acceptance of an assertion or an apology doesn't just put one in a different epistemic position with respect to the facts but brings with it certain vulnerabilities and responsibilities of its own. Accepting an apology, for instance, brings with it the responsibility to put away one's resentment, and makes one vulnerable to a particularly bruising possibility of deceit. These risks are avoided by simply taking the apology as more or less good evidence for remorse, and then making of it what one will.

The Evidential View puts speaker and audience into disharmony with each other in mislocating the connection between what the speaker does and the fact that it provides a reason for belief. From the speaker's point of view it is not a matter of what his behavior passively indicates, but a matter of what he then and there presents himself as assuming re-

${ }^{27}$ Anscombe, p. 150. See also Austin, p. 100.

\section{Getting Told and Being Believed}

sponsibility for. Unlike an evidential relation, the connection between the speaker's words and what he asserts or what he promises is entirely at his disposal to declare or to retract. The possibility of such retraction is central to the meaning of speech acts of assertion, promising, and the like, and shows how different they are in meaning and consequence from other actions. The speaker alone has the authority to bestow such epistemic import on his words, or to cancel it; whereas he speaks with no such authority over the evidential import of anything he does or says.

Speaking of course is an action; something with consequences in the world like other actions, and which leaves behind evidence of itself. But the exclusivity of the speaker's authority shows that retracting one's words is not to be confused with undoing the consequences of an action that went wrong. Often enough, another person could in principle clean up after the mess I made as well as I. But no one else can take back what I said. And, of course, taking back what I said does not make it as if it never happened. After I've taken back what I said it may still take a long time for me to undo the damage my hard or thoughtless words have caused. But that doesn't mean that taking them back doesn't accomplish anything, that I might just as well not have returned to them. There's still an important difference in the situations before and after the angry words are retracted. Indeed, taking them back was a prior condition for the more practical (or consequential) work of starting to try to undo the damage they caused. And that's a different kind of task. I cannot "hereby" undo the damage, the hurt feelings I caused; that takes consequential work, which may fail in unforeseen ways, like any other action. But again, that doesn't mean that the sort of thing I can accomplish "hereby" is something I perform magically or effortlessly, or that it may not be something I can only manage with great difficulty. It 


\section{Richard Moran}

will, however, be a different kind of difficulty from that involved in repairing the actual damage. If I try and fail here, at the level of retraction or apology, it will not be for reasons of unforeseeable accidents, or the general resistance of the world to our wills. ${ }^{28}$

\section{BIBLIOGRAPHY}

Anscombe, G.E.M., "What Is It To Believe Someone?", in Rationality and Religious Belief, ed. C.F. Delaney (Notre Dame, 1979)

Anscombe, G.E.M., "Faith", in Ethics, Religion and Politics: Collected Philosophical Papers, Vol. III (University of Minnesota, 1981)

Austin, J.L., How To Do Things With Words (Harvard, 1962)

Austin, J.L., "Other Minds", in Philosophical Papers (Oxford, 1979)

Brandom, Robert, Making It Explicit (Harvard, 1994)

Burge, Tyler, "Content Preservation", Philosophical Review, vol. 102, 1993, pp. 457-88

Cavell, Stanley, The Claim of Reason (Oxford, 1979)

Coady, C.A.J., Testimony: A Philosophical Study (Oxford, 1992)

${ }^{28}$ This paper has a long history and I have accumulated more than the usual share of debts along the way. In presenting both this and related material, I have benefitted from responses of audiences at: Wake Forest University; Arizona State University; University of Wisconsin, Milwaukee; New York University; the Center for Human Values at Princeton University; Vassar College; University of Connecticut, Storrs; Rice University; Johns Hopkins; Stanford University; Macquarrie University, Sydney; University of Pennsylvania; Amherst College; University of Virginia; Columbia University; University of Chicago; and the University of Minnesota. Earlier versions of this material were presented at the Third Italian American Philosophy Conference, Rome and Frascati, June 2001; and at the Instituto de Investigaciones Filosoficas, UNAM, Mexico City. I am grateful to my hosts on those occasions.

I also received valuable comments from Jonathan Adler, Tyler Burge, Mario De Caro, Kate Elgin, Paul Faulkner, Luca Ferrero, Amy Gutmann, Paul Harris, Pamela Hieronymi, Karen Jones, Adam Leite, Wolfgang Mann, Peter de Marneffe, Ed Minar, David Owens, Connie Rosati, Angus Ross, Nishi Shah, Martin Stone, David Sussman, Michael Thompson, David Velleman, Jonathan Vogel, Matthew Weiner, Daniel Weinstock, as well as the helpful reports of two anonymous referees.

\section{Getting Told and Being Believed}

Darwall, Stephen, The Second-Person Standpoint: Morality and Accountability (forthcoming).

Grice, H.P., "Meaning", Philosophical Review, vol. 66, 1957, pp. 377-388. Reprinted in Grice, Studies In The Way Of Words (Harvard, 1989).

Harman, Gilbert, Change In View (MIT, 1986)

Holton, Richard, "Deciding to Trust, Coming to Believe", Australasian Journal of Philosophy, vol. 72, 1994, pp. 63 - 76

Hume, David, “On Miracles”, in An Enquiry Concerning Human Understanding (Hackett, 1977)

Leite, Adam, "On Justifying and Being Justified", Philosophical Issues (a supplement to Nô̂s), vol. 14, 2004, pp. 219 253

Locke, John, Essay Concerning Human Understanding, ed. Peter Nidditch (Clarendon Press, 1975)

Moran, Richard, "Problems of Sincerity", in Proceedings of the Aristotelian Society, vol. CV, part 3, 2005, pp. 341-61

Quine, W.V.O., and Ullian, J.S., The Web of Belief (New York, 1970)

Ross, Angus, “Why Do We Believe What We Are Told?”, Ratio, vol. 28, 1986, pp. 69-88

Stone, Martin, "The Significance of Doing and Suffering", in Philosophy and Tort Law, ed. G. Postema (Cambridge, 2001)

Stone, Martin, "On the Idea of Private of Law", Canadian Journal of Law and Jurisprudence, vol. IX, 1996, pp.253-77. Reprinted in Tort Law, The International Library of Essays in Law and Legal Theory, 2nd Series, ed. E. Weinrib (Ashgate Publishing, 2003).

Strawson, P.F., "Freedom and Resentment", in his Freedom and Resentment (Methuen, 1974), pp. 1 - 25.

Thompson, Michael, “What Is It To Wrong Someone? A Puzzle About Justice", in Reason and Value: Themes from The Moral Philosophy of Joseph Raz, ed. R.J. Wallace, Philip 
Pettit, Samuel Scheffler, and Michael Smith (Oxford, 2004)

Traiger, Saul, "Humean Testimony", Pacific Philosophical Quarterly, vol. 74, 1993, pp.135-49

Walton, Kendall, "Transparent Pictures: On the Nature of Photographic Realism", Critical Inquiry, vol. 11, 1984, pp. 246-77

Watson, Gary, "Asserting and Promising", Philosophical Studies, vol. 117, 2004, pp. 57-77

Weinrib, Ernest, The Idea of Private Law (Harvard, 1995)

Welbourne, Michael, The Community of Knowledge (Aberdeen, 1986)

Williams, Bernard, Truth and Truthfulness: An Essay in Genealogy (Princeton, 2002)

Williamson, Timothy, "Knowing and Asserting", Philosophical Review, vol. 105, 1996, pp. 489-522. Reprinted in his Knowledge And Its Limits (Oxford, 2000).

Wittgenstein, Ludwig, Remarks on the Philosophy of Psychology, vol. I, translated by G.E.M. Anscombe (Blackwell, 1980) 